\title{
Marvellous Muscodor spp.: Update on Their Biology and Applications
}

\author{
Sanjai Saxena ${ }^{1}$ (D) Gary A. Strobel ${ }^{2}$ (D) \\ Received: 17 September 2020 / Accepted: 12 November 2020 / Published online: 24 November 2020 \\ (C) Springer Science+Business Media, LLC, part of Springer Nature 2020
}

\begin{abstract}
Nearly 20 years ago, the first report appeared on the discovery of a novel genus-Muscodor. This organism was isolated as an endophyte from a cinnamon tree that had been introduced to Honduras from Sri Lanka in the early part of the last century. Characteristically, the original Muscodor albus, and all of its species isolated since that time are non-spore producers and each one exudes a characteristic spectrum of volatile bioactive compounds. The majority have a whitish mycelium, which is sometimes coiling, intertwined and decorated with variously shaped structures. Presently, there are at least 22 type species known/ documented and each has been described as an endophyte from various plant families with widely varying habitats. An enormous variety of volatile organic compounds (VOCs) are produced by Muscodor spp. and some of these include esters, acids, aldehydes, ketones, aromatics, alkanes, alcohols, nitrosamides and terpenoids. The VOCs are both inhibitory and lethal to a wide variety of fungi and bacteria including some major pathogens of plants and humans. Interestingly, in almost all cases studied, no one compound by itself can mimic the bioactivity of the complete gas mixture, suggesting that the volatiles are acting in a synergistic manner and this has been tested with individual as well as the VOCs in various mixtures and concentrations. This review will discuss some of the recent findings in all aspects of this unique fungal genus whilst at the same time pointing out some of the major questions that remain about its biology, ecology and its applications in agriculture, medicine and other sectors. Most importantly, the authors provide arguments supporting the claim that Muscodor is taxonomically distinct from Induratia, a recently proposed change to its nomenclature.
\end{abstract}

Keywords VOCs (volatile organic compounds) $\cdot$ Synergistic activity $\cdot$ Muscodor $\cdot$ Antimicrobial activity $\cdot$ Mycofumigation

\section{Introduction: Serendipity-Finding a Novel Fungus (a Personal Recollection)}

Over the years, many people have asked — how did you (Gary Strobel) possibly have found the first Muscodor spp.? The answer is totally grounded in scientific serendipity. In 1997, I was on a collecting trip in the jungles of the Caribbean coast of Honduras, one of the world's 'hot spots of biodiversity'.

\section{Sanjai Saxena}

sanjaibiotech@yahoo.com; ssaxena@thapar.edu

Gary A. Strobel

uplgs@montana.edu

1 Department of Biotechnology, Thapar Institute of Engineering and Technology, Patiala, Punjab 147004, India

2 Department of Plant Sciences and Plant Pathology, Montana State University, Bozeman, MT 59717, USA
The Dole Fruit Company indicated that if I was to help them with a number of disease problems they were having in their crops, they would take me to some collecting points for tropical plants. I was interested in acquiring as many tropically diverse plants as possible to eventually study the novelty of endophytes and bioactive secondary product formation in them. I was eventually led to the Lancetilla Botanical Garden near La Ceiba, Honduras. It is not often that I ever make any plant collections in or around botanical gardens since they are usually located in metropolitan areas. The smog and industrial pollution in these areas generally limit biodiversity of endophytes in these plants. However, to my amazement, this garden was well removed from any major city. It was a great place to visit since many tropical plants from around the world had been planted there nearly a century before in order to learn which ones eventually may serve for agricultural purposes in that area. One modestly sized tree, not native to the new world, was introduced to me as Cinnamomum 
zeylanicum. Small limb specimens were taken and placed in a plastic bag and brought back to Montana.

Coincidentally, in the laboratory, my group of scientists had been plagued with microscopic phytophagous mites in the lab for many months. This is not uncommon for labs in which plant materials are being processed on a regular basis. These nasty creatures infest the benchtops and find Petri plates containing agar in which to take up residence. They can easily navigate their way through a parafilm seal on Petri plates and eventually infest the agar surface. If they make their move on an agar plate sporting fungi, one can never know that they are present unless the hyphae are carefully examined under a binocular microscope. However, if an infested culture is transferred to a liquid broth medium, it will turn cloudy with bacterial growth overnight.

Thus, in order to eliminate this nagging mite problem, we treated all plant tissues from the Honduras collection with 95\% ethanol and then flamed them. This treatment effectively killed all of the mites as well as surface contaminating microbes. The plates were handled in a biosafety hood that was free of any mites. Then, we placed the plates (free of mites) in a large plastic box making it difficult for the tiny animals to find their way from the untreated bench surfaces to the inside of the box and ultimately to the inside of the plates. After a few days, most plant specimens had sported endophytic fungal growth. The plates were incubated for another week until the colonies grew a bit larger for hyphal tip isolation procedures. When the lid of the box was opened, a strange odour emerged. Plates were removed and the individual hyphae transferred to fresh plates of potato dextrose agar. After 3 days of incubation, no transferred endophyte grew except one. Had the placement of the endophytes in the large plastic box killed the endophytes by limiting oxygen availability? Should we continue to use the boxes as barriers to mites? Then, it became obvious that the one endophytic fungus (designated isolate 620 ) remaining alive was producing bioactive VOCs. When the original culture of this lone living endophyte was 'sniffed', it seemed to be producing the same odour as that in the box when it was originally opened. The hypothesis that an endophyte can make volatile antibiotic substances with a wide range of biological activity was born. We had an experience of serendipitous discovery of an extremely useful VOC producing endophytic fungus similar to penicillin as experienced by Sir Alexander Fleming whilst reporting the first antibiotic 'penicillin' in the processes of trying to free our cultures of mites.

A literature search revealed that many wood-inhabiting fungi make volatile substances which are considered air contaminants. Interestingly, none had been demonstrated to have wide-ranging and potentially useful lethality to other microbes when compared to isolate 620 . Because of its uniqueness structurally, biochemically and genetically, the fungus 620 was designated as Muscodor albus [1,2]. Ever since the discovery of Muscodor albus, many species were reported from different regions of the globe wherein their taxonomic, biological and utilitarian properties were examined. Although several reviews on Muscodor appeared about a decade ago, it appears that the time is at hand for an update on this important fungal genus [3-6]. Therefore, this review will discuss recent developments in several biological aspects of genus Muscodor and describe how the organism and its products have been utilized in agriculture, industry and the medical fields.

\section{Muscodor Taxonomy-a Recent Question?}

When Muscodor albus was first described it was done in a manner that conformed to all of the nomenclature conventions at the time [1, 2]. Recently, however, Samarakoon et al. [7] proposed that the Muscodor genus be ascribed to the genus Induratia by virtue of its phylogenetic relatedness to the xylariaceous genera Emarcea and Induratia. This conclusion was entirely based on sequence relatedness data from 4 genes-ITS, LSU, $r p b 2$ and $t u b 2$, inconclusive and narrow screening results for VOC bioactivities, and GC/MS studies showing little or no matching data with most Muscodor spp. Despite their claim of Muscodor having similarities with Emarcea and Induratia, they are non-conclusive on the basis of morpho-taxonomy. Ascospores/Apiospores which are characteristic features of the Induratia family have only been morphologically presented in the case of Induratia ziziphi and Induratia thailandica, the two new species which are reported by them under this family. However, previously reported Muscodor species, viz. M. equisetii, M. cinnamomi and M. musae, have not been shown to produce Ascospores/ Apiospores nor, in fact, has any other isolate of Muscodor since its initial discovery. Whilst it is noteworthy, these workers correctly pointed out the fact that the amassed molecular genetic data do support the fact that Muscodor is a xylariaceous fungal genus, numerous questions might remain about the renaming of this well-established fungal genus.

Thus, again to emphasize, all Muscodor spp. that have been studied have sterile hyphae and thus no spores have ever been noted when grown on multiple media and host materials which are in sharp contrast to Induratia sp. that make Nodulisporium like spores and conidiophores [7]. Also, Samarakoon et al. [7] argue that the ITS sequence region of Induratia is remarkably similar to Muscodor and since the former was named first, subsequently all Muscodor sp. should now be included as Induratia sp. [7]. This argument cannot be considered as a baseline rule since it is commonly observed that ITS sequence data alone can be totally misleading as noted by Xie et al. in work done on a novel Collophora spp. [8]. Furthermore, Chen et al. have provided molecular genetic arguments that support the taxonomic position of Muscodor 
as a distinct genus [9]. VOC signatures of Muscodor spp. play an important role in their taxonomic positioning as well as contribute to their taxonomic characteristics. The VOC chemistry of the Induratia spp. is totally dissimilar to each of the Muscodor species that have been isolated and studied [3-7] (Tables 1 and 2). Samarakoon et al. represent their compound concentration data in an obscure manner of peak intensities whereas the standard procedure involves the representation of percentage peak area [7]. Most importantly, some of the Muscodor sp. release isobutyric acid which is central to its bioactivity and apparently results from the breakdown of $n$ methyl nitrosoisobutyramide which is extremely unstable [10-12]. This amide has also been implicated in the bioactivity of the VOCs of Muscodor by virtue of its action on target host DNA, but this assertion can be questioned since artificial mixtures of the VOCs, not containing the nitroisobutyramide, completely mimic the activity of the fungus itself $[2,11,12]$. In addition, generally, the Muscodor spp. possess a wide spectrum of antifungal and antibacterial activities quite unlike Induratia sp. [2-7] (Table 1). Finally, Induratia sp. have only been isolated from dead plant materials in tropical areas [7] unlike the Muscodor spp. which appear solely as endophytes in tropical [3-6] as well as temperate [13] and xeric environments [14] (Table 1). Basically, it defies all mycological taxonomic and biological reasoning that a multitude of independent investigators from around the world, having isolated and thoroughly studied a bioactive endophytic sterile fungus (Muscodor sp.) from a plethora of plant families, should now be asked to accept the concept that Muscodor be reassigned to the genus Induratia on the basis of a weak biological rationale and poorly done experimentation. If any question remains about the unique status of genus Muscodor, then the ultimate answer may be found by doing the complete genome sequence of Induratia sp. and comparing it to that of Muscodor albus which has recently been sequenced by Britany Pierce at Marrone Bio Innovations (MBI) in Davis Calif. [Pamela Marrone, unpublished]. In summary, the authors of this review strongly refute the weak claims that Muscodor spp. be relegated to the genus Induratia sp.

\section{The Ecology of Muscodor spp.}

Whilst much is known about the biology and chemistry of Muscodor sp. under laboratory conditions, little is known about it in its natural environment [3-6]. It has only ever been isolated as an endophyte. That is to say, plants that host Muscodor spp. show no evidence of its presence via fungus

Table 1 Comparison of characters of the genera Muscodor and Induratia

\begin{tabular}{|c|c|c|c|}
\hline Characteristic feature & Genus-Muscodor & Genus-Induratia & Conclusions \\
\hline Spore production & $\begin{array}{l}\text { None ever noted among all } \\
\text { observers on } 4 \text { continents }\end{array}$ & $\begin{array}{l}\text { Conidiospores borne on } \\
\text { conidiphores similar } \\
\text { to Nodulisporium }\end{array}$ & $\begin{array}{l}\text { The two genera are different } \\
\text { with respect to spore production }\end{array}$ \\
\hline Gene sequence similarities & ITS sequences similar to Induratia & $\begin{array}{l}\text { ITS and } 3 \text { other genes similar } \\
\text { to Muscodor }\end{array}$ & $\begin{array}{l}\text { Shared sequence similarities of } 4 \text { genes } \\
\text { but with some isolates* }\end{array}$ \\
\hline Bioactivities of VOCs & $\begin{array}{l}\text { Strong activity towards many microbes, } \\
\text { nematodes and insects. }\end{array}$ & Weak antibacterial activity only & $\begin{array}{l}\text { The two genera do not share wide } \\
\text { anti-pest activities or characteristics }\end{array}$ \\
\hline Life preferences & $\begin{array}{l}\text { - Always found in the endophytic state, } \\
\text { has not been isolated from plant litter } \\
\text { - Does not survive in dead plant material } \\
\text { in or on soil for more than 3-4 days } \\
\text { - Found in tropical, temperate and xeric } \\
\text { environments }\end{array}$ & $\begin{array}{l}\text { Primarily found to be associated } \\
\text { with dead stems or plant litter; } \\
\text { exists in tropics only }\end{array}$ & $\begin{array}{l}\text { The two genera have entirely } \\
\text { different habitat preferences. }\end{array}$ \\
\hline Chemistry of VOCs & $\begin{array}{l}\text { A wide range of products are formed: } \\
\text { acids, esters, alcohols, aromatic } \\
\text { compounds, terpenoids among many } \\
\text { others }\end{array}$ & $\begin{array}{l}\text { Many terpenoids, one ester and no } \\
\text { low molecular weight } \\
\text { (MW) organic acids, and a } \\
\text { listing of chloroform }\end{array}$ & $\begin{array}{l}\text { There are striking differences } \\
\text { between the two genera based } \\
\text { on their volatilome }\end{array}$ \\
\hline $\begin{array}{l}\text { Molecules needed for } \\
\text { strong bioactivity }\end{array}$ & $\begin{array}{l}\text { Isobutyric acid is a key VOC associated } \\
\text { with bioactivity of most isolates }\end{array}$ & $\begin{array}{l}\text { Isobutyric acid is not } \\
\text { reported from this organism }\end{array}$ & $\begin{array}{l}\text { A critical acid for wide-ranging } \\
\text { bioactivity is not present } \\
\text { in Induratia }\end{array}$ \\
\hline $\begin{array}{l}\text { Molecules needed for } \\
\text { maximum } \\
\text { bioactivity via testing of } \\
\text { synthetic mixtures }\end{array}$ & $\begin{array}{l}\text { The small MW acid, one or more } \\
\text { esters and a cyclic compound }\end{array}$ & $\begin{array}{l}\text { Compounds not present } \\
\text { and synthetic mixtures not tested }\end{array}$ & $\begin{array}{l}\text { Cannot be the same since the } \\
\text { chemistries are different }\end{array}$ \\
\hline
\end{tabular}

*The whole-genome analysis Muscodor albus has been already carried out; comparative analysis of the selected portion is inconclusive. Further similarities have to be drawn between the volatilome and metabolome to prove that Induratia and Muscodor are the same using two representatives, i.e. type species 


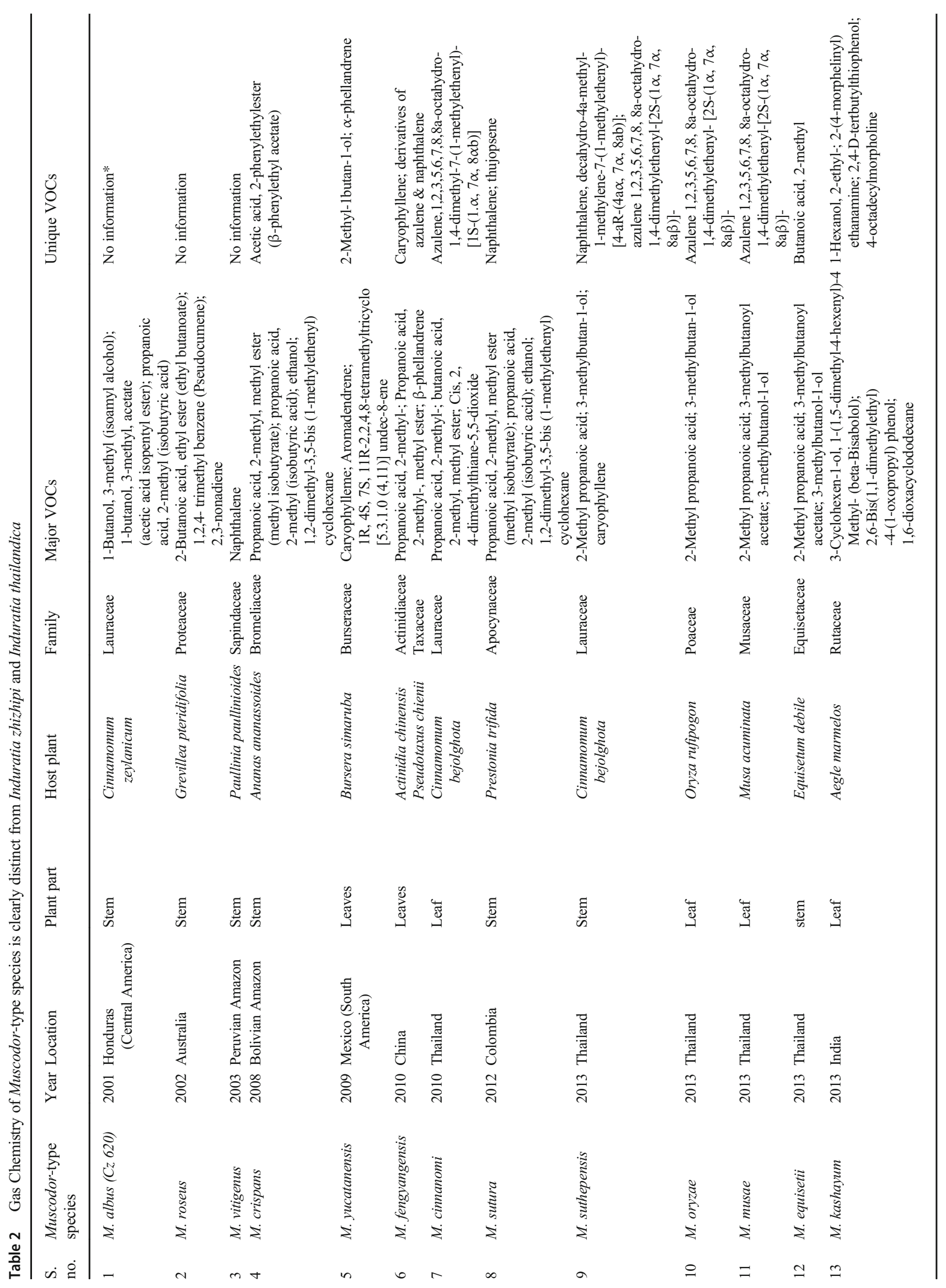




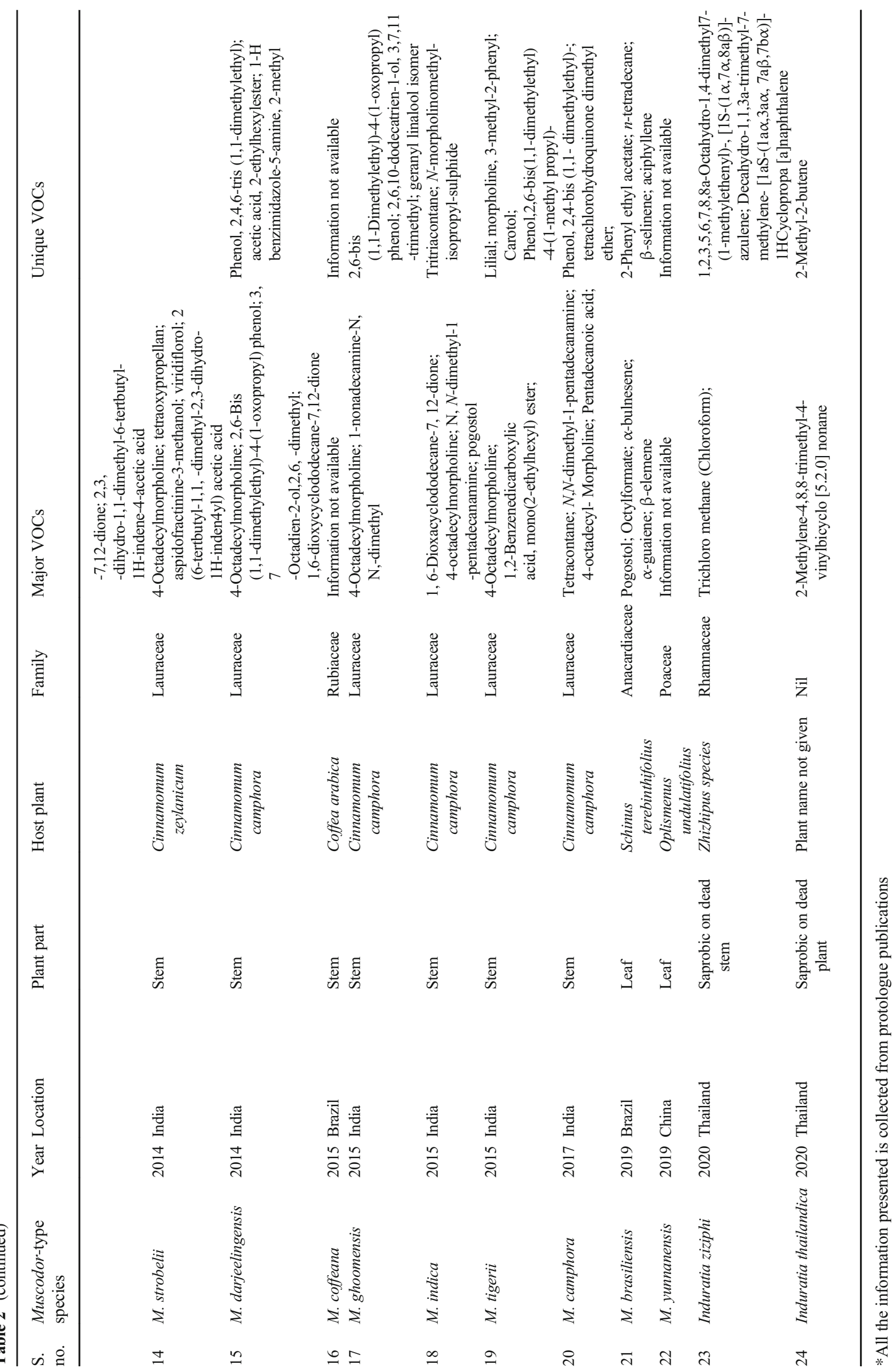


induced symptoms or the actual physical structures of the fungus itself. Basically, its life cycle is relatively unknown. No spores of the fungus have ever been noticed which begs the question as to how it might spread and become distributed in the wild (Table 1). One possibility is that it might be seedborne and become distributed in this manner, or alternatively infested plant materials, namely limbs, flowers and other plant parts that fall from the plant host, and allow for fungal distribution. This is a major question that begs many other questions about this important fungal genus. Also, only speculation exists as to how this organism may interact with its plant host. Because it produces an array of antimicrobial VOCs under laboratory conditions does not necessarily mean that it also does so in its plant host and subsequently provides protection of that host to invading pathogens. Nevertheless, there are suggestions that VOC production may be an important factor in providing protection to a plant host but there are no direct in vivo data to support this assumption. Answers to these important ecological questions would ultimately allow for an even greater spectrum of utility for this important fungal genus. For instance, one critical aspect of the biology of this fungus is the simple prospect of it being artificially introduced into a plant host. This feat was first done with M. albus in a tropical tree Guazuma ulmifolia with its successful reintroduction into the plant via inoculation of new leaves emerging from seeds that had just germinated [15]. This marks a milestone in what might eventually be the utility of this fungus as a potential natural plant protection species via plant inoculation. Of course, other important questions remain about the host range of any species of Muscodor, but the opportunities are enormous for Muscodor spp. being potentially useful in the protection of crop/forest species from important fungal and bacterial pathogens. However, to date, there are at least 20 plant families from which this fungus has been isolated (some findings not reported), but Lauraceae, from which the

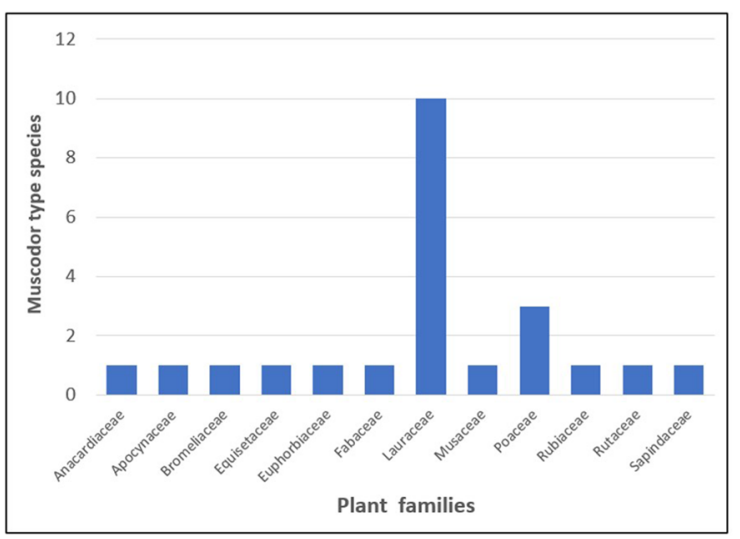

(a)
Muscodor was first reported is the most prolific host as 10 types species have been reported from it up until the present time (Fig. 1).

\section{Muscodor spp.: an Industrially Important Endophytic Genus}

Today, the Muscodor genus has 22 type species [9], and several isolates reported from the different geographic locations across the globe which are being continuously exploited for the development of numerous industrial applications, largely in the agriculture sector followed by health, environment and food (Fig. 2). Members of Muscodor genus are some of the best-studied fungi with respect to their gas chemistry (VOCs) which possess tremendous direct and indirect applications (Table 2). The number of publications and patents filed on the applications of volatile and non-volatile secondary metabolites of Muscodor spp. is continuously expanding as will be potential uses for this technology.

\section{Agricultural Applications of Muscodor}

Initially, it seemed obvious, when it was discovered over 20 years ago, that there would eventually be a plethora of uses for Muscodor and its bioactive products, especially the volatile ones. The VOCs of Muscodor albus showed enormous antimicrobial activity on pathogenic bacteria and fungi which are the main biological threats to crops at the farm level as well as after the harvest of the crop during storage and transportation. The use of M. albus has been studied as a potential replacement of methyl bromide not only for soil fumigation but also for biofumigation potential of stored fruits and vegetables. However, this could only happen after patenting processes were begun and when that occurred, an agricultural biotech company, AgraQuest in Davis Calif., licensed the fungus for

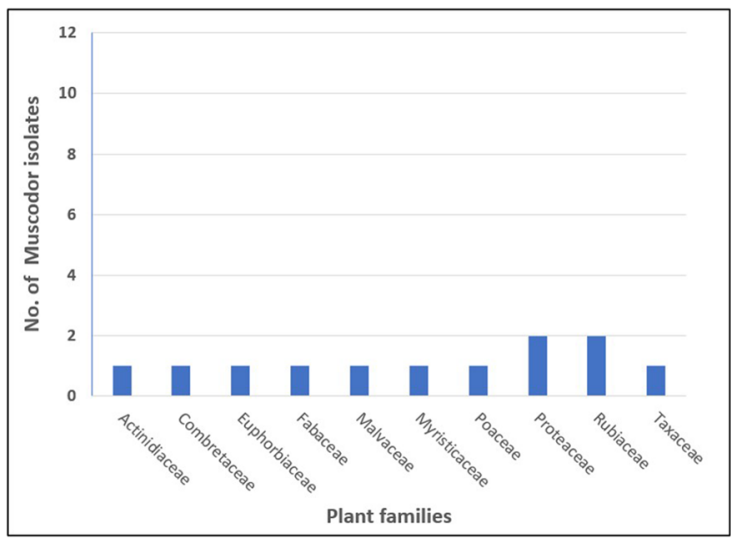

(b)

*Information collated based on protologue publications and patents

Fig. 1 Endophytic association of genus Muscodor with plant families. a Type species. b Isolates of Muscodor*. *Information collated based on protologue publications and patents 


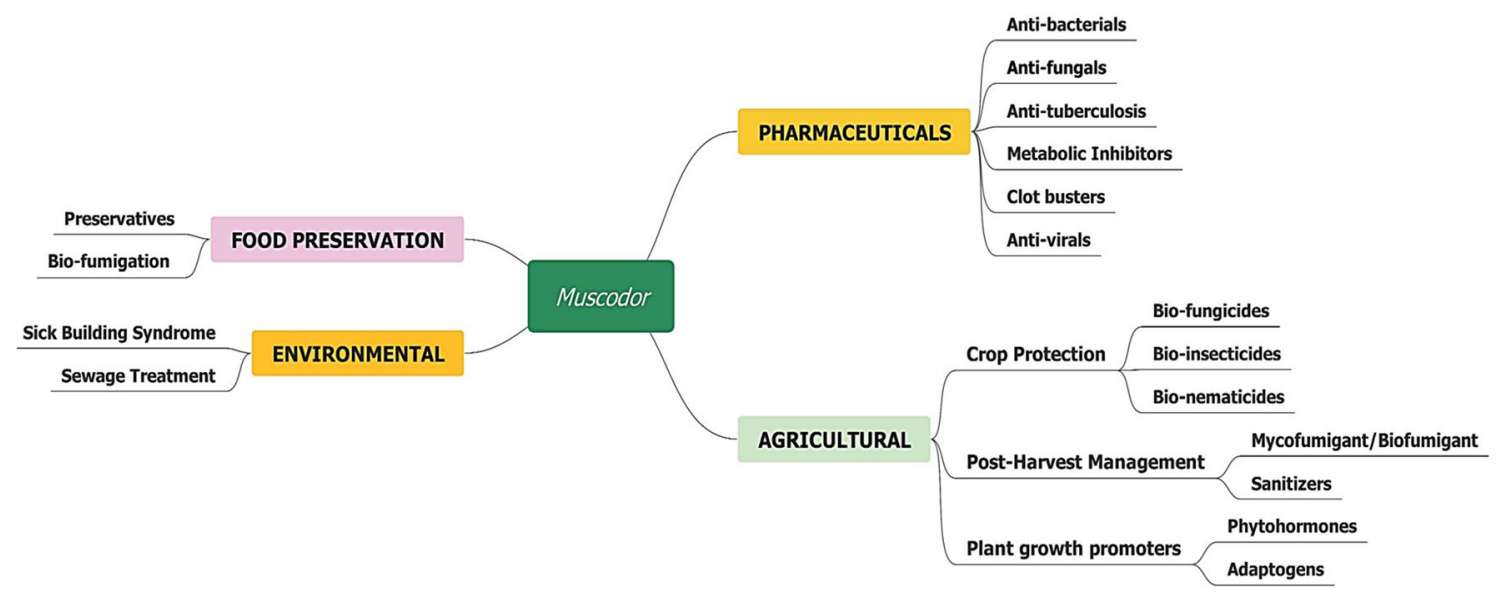

Copyright 2020, Sanjai Saxena and Gary A. Strobel

Fig. 2 Industrial applications of Muscodor spp.: An endophyte par excellence

agricultural applications. The company sponsored a myriad of tests to determine the utility of the organism to protect and preserve agricultural products as well as industrial uses. Amazingly, Mercier and colleagues had demonstrated a wide range of plant pathogenic and otherwise industrially harmful microbes that were targets of M. albus VOCs [16, 17]. EPA approval for releasing the fungus as a natural biofumigant into agricultural operations was obtained in 2005 .

\section{Role of Muscodor spp. in Crop Protection}

'Mycofumigation' concept was introduced as an eco-friendly approach to replace methyl bromide which was to be phased out in the USA in the year 2005 due to its environmental and potential negative health effects. This concept emphasized the use of VOCs produced by fungi including endophytic fungi. Several research groups have evaluated the use of Muscodor $s p$. for biofumigant applications in the field as crop protection agents as bio-fungicides, bio-insecticides and bio-nematicides. M. albus (Cz620) and M. roseus (A3-5) were formulated as soil mix for the production of VOCs which exhibited potential inhibition of soil-borne pathogens such as Rhizoctonia solani, Pythium ultimum and Verticillium dahliae during in vitro studies. The soil mix formulation of M. albus and $M$. roseous were then further tested in green house and field trials and was found to control the seedling diseases in sugar beet and Verticillium wilt in eggplant [18].

Rye grain formulation of M. albus (Cz620) in greenhouse trials completely inhibited the damping-off of broccoli seedlings caused by Rhizoctonia solani. It also controlled the root rot of Bell pepper caused by Phytophthora capsici [19]. Similar efficacy studies on VOCs of $M$. albus proved it as a potential mycofumigant to control Phytophthora blight in sweet pepper in a greenhouse trial [20]. Pythium ultimum which causes root rot in Brassica oleracea was also effectively controlled by VOCs produced by M. albus MFC2 under in vitro conditions as well as in seedling stage under field conditions [21]. Tilletia caries causes common bunt of wheat and commonly interferes in the processes of the production of organically grown wheat. The VOCs of M. albus ( $\mathrm{Cz}$ 620) were effective against Tilletia caries under field conditions [22, 23].

Several years later, however, AgraQuest learned that the organism was making $n$-methyl nitrosoisobutyramide. Such nitrosoamides, even though they are only short-lived, are well known as carcinogens, so progress on the project ceased. AgraQuest along with its product portfolio was finally acquired by Bayer CropScience in 2012 and Dr. Pam Marrone (having left AgraQuest) then started Marrone Bio Innovations (MBI) also located in Davis, CA, acquired a plethora of other Muscodor albus isolates from Gary Strobel which were not producing the nitrosoamides and picked the most promising one for product development $M$. albus SA-13. This organism did not make any detectable $n$-methyl nitrosoisobutyramide and now has both EPA and State of California registrations for agricultural applications. Its initial use was directed towards soil decontamination, after having been grown on barley seed, dried and then placed into soil that would eventually be planted to high-value crops such as strawberries, celery and potatoes and is a targeted replacement product for methyl bromide use in agriculture. Field studies have effectively demonstrated the utility of the use of this isolate in effectively protecting plants from disease development. It has been named Ennoble ${ }^{\mathrm{TM}}$ [P. Marrone, personal communication]. It is obvious that there are many hurdles in getting a product to the marketplace. The main challenge now is finding a way to make the product economically feasible [P. Marrone, personal communications].

Novel species of Muscodor from different ecological niches are constantly being isolated and explored for their 
unique gas chemistries and biological activities whilst being evaluated for possible exploitation in the agriculture as well as pharmaceutical sectors. The VOCs produced by Muscodor cinnamomi CMU-Cib461 isolated from Cinnamomum bejolghota exhibited the potential to control tomato root rot caused by Rhizoctonia solani AG2 apart from promoting plant growth [24]. Another novel species, M. heveae, isolated from leaves of rubber tree elaborated VOCs which could effectively control root rot disease caused by Phellinus noxius and Rigidisporus microspores in rubber trees [25]. Furthermore, this group exclusively tested VOCs from $M$. heveae against white root rot disease in rubber tree and concluded that exploitation of VOCs of $M$. heveae would be an alternative method for controlling this major disease [26]. Another novel strain of Muscodor which exhibited bio-fungicidal potential was LGMF1254, possessing high similarity to Muscodor sutura phylogenetically. LGMF1254 was isolated from Citrus sinensis exhibited a potent activity against citrus blackspot fungus, Phyllosticta citricarpa [27]. In fact, it seems that this isolate of Muscodor, having been isolated from citrus, should be tested for its activity against citrus greening disease caused by Candidatus liberibacter one of the most important plant diseases in the world. Apart from these which have been tested, other potential Muscodor species exhibiting biofungicidal potential against wide range of phytopathogenic fungi comprise of Muscodor crispans [28], Muscodor kashayum [29], Muscodor suthepensis, Muscodor musae, Muscodor oryzae, Muscodor equiseti [30] and Muscodor strobelii [31] (Table 3).

Parallel to these studies, the potential of VOCs from Muscodor species was also being explored for possible use as bio-insecticides and bio-nematicides. Muscodor vitigenus which was isolated from Paullinia paullinoides in Peru repelled Cephus cinctus (wheat stem saw fly) which was attributed to the controlled production of naphthalene and its derivatives, naphthalene, 2-methyl and naphthalene,1-methoxy in traces. The other compounds in the gas mixture comprised of $M$. vitigenus comprising benzaldehyde, butylated hydroxytoluene and toluene apart from the traces of caryophyllene, acetone and azulene, 1,2,3,5,6,7,8,8a-octahydro-1,4-dimethyl7-(1-methylethenyl)-, [1S-(1. $\alpha ., 7 . \alpha ., 8 \alpha . \beta)$.$] . Naphthalene is$ a relatively rare natural product but its presence in a fungus (M. vitigenus) was the first report in fungi. However, it is well known as an antimicrobial agent, insecticide and insect repellent and also as a vermicide [32,33]. Subsequently, interest developed among entomologists to explore the volatiles of M. albus (Cz620), as an alternative strategy to replace/ reduce the dependence of broad-spectrum chemical insecticides. The premise of this exploration was the biocidal activity of $M$. albus volatiles against a variety of organisms.

Rhagoletis indifferens Curran (Diptera; Tephritidae) commonly known as western cherry fruit fly is a major pest of sweet cherry (Prunus avium (L.)) and is generally controlled using conventional insecticides. A study conducted to assess the potential of VOCs of M. albus on pupae of $R$. indifferens apart from adult emergence rate under laboratory conditions exhibited a significant reduction $(\sim 62 \%)$ in the emergence of fly pupae. A 14-day exposure however enhanced the reduction in fly emergence to $\sim 86.3 \%$. From this study, it could be concluded that high concentration and prolonged exposure of VOCs are responsible for significant mortality of $R$. indifferens pupae in the soil. Subsequently, this study served as a primer for several evaluations of M. albus VOCs for their presumptive applications as a biorational broadspectrum insecticide [34]. Cydia pomonella (L.) aka codling moth is also posing a serious threat to apples during storage and transportation. Yet another factor which provides an edge to this insect pest is insecticide resistance which enables it to survive as larvae within as well as emerging from fruits [35]. This is posing a severe threat to export of apples and other fruits outside of the USA. Previously, fumigation was a common principal method for protection of fruits which were to be exported; therefore, the VOCs of M. albus were considered as a prospective alternative to methyl bromide for prevention of the codling moth. Promising results were obtained on fumigation by VOCs of M. albus different stages of the codling moth which further strengthened the case for Muscodor VOCs to be used as biofumigants to control insect pests [36]. The control of potato tuber moth (PTM) was also enhanced by the use of M. albus VOCs at low temperature apart from attack by plant pathogens [37]. Incidentally, all these studies on insect control using Muscodor VOCs were done by USDA (United States Department of Agriculture). Plant-parasitic nematodes have a tremendous impact on agriculture having economic implications. Four nematodes which drastically affect crops are Meloidogyne chitwoodi, Meloidogyne hapla, Paratrichodorus allius and Pratylenchus penetrans. Though chemical fumigants such as 1,3-dichloropropene are frequently used to control nematodes; however, it is expensive and non-environment friendly. With worldwide emphasis on organically grown food, a biofumigant could possibly be the right sustainable alternative for the control of plant-parasitic nematodes. Hence, it was imperative to assess the VOCs of Muscodor albus for their possible use as biofumigant against plant-parasitic nematodes. Riga et al. [38] proved that VOCs of $M$. albus possessed both nematicidal and nematostatic properties under greenhouse conditions. The nematostatic activity was associated with the nematodes residing in the host roots of potato, pepper, tobacco and beans whilst nematicidal properties were observed in the soil.

Biorational mixture of volatiles (made by mixing the commercially available components of the VOCs analysis of M. albus) was comparatively assessed with VOCs of M. albus for their potential to control seedling and root-knot nematode diseases. The biorational mixture was efficacious over M. albus formulation used for soil fumigation to control 
Table 3 Bio-fungicidal potential of Muscodor species*

\begin{tabular}{|c|c|c|c|c|c|c|c|c|c|}
\hline $\begin{array}{l}\text { S. } \\
\text { no. }\end{array}$ & Muscodor species & $\begin{array}{l}\text { Penicillium } \\
\text { sp. }\end{array}$ & $\begin{array}{l}\text { Rhizoctonia } \\
\text { solani }\end{array}$ & $\begin{array}{l}\text { Botrytis } \\
\text { cinerea }\end{array}$ & $\begin{array}{l}\text { Cercospora } \\
\text { beticola }\end{array}$ & C. gloeosporioides & $\begin{array}{l}\text { Fusarium } \\
\text { sp. }\end{array}$ & $\begin{array}{l}\text { Alternaria } \\
\text { sp. }\end{array}$ & $\begin{array}{l}\text { Aspergillus } \\
\text { sp. }\end{array}$ \\
\hline 1 & M. albus $(C z$ 620) & $\mathrm{NE}$ & ++++ & ++++ & + & NE & ++ & NE & ++++ \\
\hline 2 & M. roseus & NA & NA & NA & NA & NA & NA & NA & NA \\
\hline 3 & M. vitigenus & NA & NA & NA & NA & NA & NA & NA & NA \\
\hline 4 & M. crispans & ++++ & ++++ & ++++ & $\mathrm{NE}$ & ++++ & ++++ & ++++ & +++ \\
\hline 5 & M. yucatanensis & $\mathrm{NE}$ & ++++ & $\mathrm{NE}$ & $\mathrm{NE}$ & ++++ & ++++ & ++++ & $\mathrm{NE}$ \\
\hline 6 & M. fengyangensis & + & ++++ & ++++ & $\mathrm{NE}$ & ++++ & + & NE & ++++ \\
\hline 7 & M. cinnanomi & NA & ++++ & NA & NA & NA & NA & NA & NA \\
\hline 8 & M. sutura & $\mathrm{NE}$ & ++++ & ++++ & ++++ & ++++ & $\mathrm{NE}$ & $\mathrm{NE}$ & $\mathrm{NE}$ \\
\hline 9 & M. suthepensis & ++++ & ++++ & ++++ & $\mathrm{NE}$ & ++++ & ++++ & ++++ & ++++ \\
\hline 10 & M. oryzae & ++++ & ++++ & +++ & $\mathrm{NE}$ & ++++ & +++ & ++++ & ++++ \\
\hline 11 & M. musae & ++++ & ++++ & +++ & $\mathrm{NE}$ & ++++ & +++ & ++++ & +++ \\
\hline 12 & M. equisetii & ++ & +++ & ++++ & $\mathrm{NE}$ & ++++ & ++++ & ++++ & ++++ \\
\hline 13 & M. kashayum & ++++ & ++++ & ++++ & ++++ & ++++ & ++++ & ++ & ++ \\
\hline 14 & M. strobelii & ++++ & +++ & ++++ & ++ & +++ & + & $\mathrm{NE}$ & ++++ \\
\hline 15 & M. darjeelingensis & NI & + & + & + & + & ++ & ++ & + \\
\hline 16 & M. coffeanum & NA & ++++ & ++++ & NA & NA & +++ & NA & ++++ \\
\hline 17 & M. ghoomensis & ++ & +++ & ++ & +++ & ++ & + & ++ & + \\
\hline 18 & M. indica & + & + & ++ & +++ & ++ & ++ & ++ & + \\
\hline 19 & M. tigerii & ++ & +++ & + & ++++ & NI & ++ & ++++ & ++ \\
\hline 20 & M. camphora & ++ & +++ & + & +++ & +++ & + & ++ & $\mathrm{NE}$ \\
\hline 21 & M. brasiliensis & ++++ & NA & NA & NA & NA & NA & NA & NA \\
\hline 22 & M. yunnanensis & NA & NA & NA & NA & NA & NA & NA & NA \\
\hline
\end{tabular}

*The data presented has been collected and collated from protologue publications/patents. $N A$, not available; $N E$, not evaluated; $N I$, no inhibition

nematodes [39]. This study opened up avenues for development of biomimetic biorational compositions of VOCs emitted by Muscodor species for their evaluation and possible development for crop protection.

\section{Post-Harvest Applications of Muscodor}

The role of VOCs of M. albus in crop protection opened up avenues in assessing their role for possible prevention of postharvest disease and decay as a plausible alternative treatment in reducing losses during storage and transportation of the fruits and vegetables $(F \& V)$. Fumigation is generally regarded as a preferred method for handling commodities for postharvest disease control. The use of chemical fumigants has a limited application window due to their side effects on users and the environment. Furthermore, societal perception also favours organic technologies that have minimal risk. Hence, organic compounds (aromatics) have been introduced which are generally comprised of essential oils (volatilized) followed by exposure of the post-harvest produce for a duration between $1 \mathrm{~h}$ and 10 days to prevent microbial decay and spoilage. However, this technology proved to be a cost-intensive proposition [40].
Mercier and Jimenez at AgraQuest then evaluated the decay control in apples and peaches by using M. albus volatiles as they killed a broad spectrum of fungal storage pathogens such as Rhizopus, Penicillium, Colletotrichum, Geotrichum and Botrytis. Using VOCs of Muscodor proved advantageous over the essential oil volatilization method in terms of resourcing and delivery of the compounds as well as their effectiveness. The VOCs of $M$. albus only required an exposure duration of 24-72 $\mathrm{h}$ to effectively control the two serious decay/spoilage pathogens blue mould (Penicillium expansum) and grey mould (Botrytis cineria) in apples and peaches. The major VOCs which played role in the decay control were isobutyric acid and 2-methyl-1-butanol. The sterility of Muscodor albus proved to be very beneficial in developing a contactless delivery system of volatiles using a grain culture technique [41].

Penicillium digitatum and Geotrichum citri-aurantii are responsible for green mould and sour rot of lemons, respectively, which were effectively controlled by $M$. albus VOCs after exposure for $48 \mathrm{~h}$ and thus proved to be a promising solution to control the decay of lemons under storage or in shipping packages [42]. Muscodor pad-based delivery systems were an effective biofumigation intervention to control 
brown rot caused by Monilinia fruticola under cold storage conditions [43]. Mercier also was instrumental in coordinating trials of colonized rye grain (Secale cereale) by other groups. Another trial in Canada was conducted on five different cultivars of apples, viz. 'Red Delicious', 'Golden Delicious', 'Gala', 'Granny Smith' and 'McIntosh'. Muscodor albus VOCs were able to control Botrytis cineria, Penicillium expansum and Sclereotinia sclerotium [44]. Mycofumigation with VOCs of Muscodor exhibited a promising antibacterial effect against, Pseudomonas fluorescens, Escherichia coli, Listeria innocua and Erwinia carotovora pv. carotovora under temperature and atmospheric controlled conditions. It proved to be useful intervention for post-harvest preservation under low temperature [45]. Furthermore, organically grown table grapes of Thompson seedless and Red seedless exhibited the least decay incidence when a combination of atmospheric liners with $M$. albus sachets were used thereby enhancing their shelf life significantly [46]. Furthermore, a combination of Muscodor biofumigation and ozone fumigation was an effective alternative to control grey mould in organically grown grapes [47]. M. albus biofumigation also played a significant role in control of post-harvest diseases such as dry rot (Fusarium sambucinum) and soft rot (Pectobacterium atrosepticum) development and also controlled the silver scurf (Helminthosporium solani) in Potato tubers at stored at $8{ }^{\circ} \mathrm{C}$ and $22{ }^{\circ} \mathrm{C}$ [48].

A new strain of Muscodor albus, aa3 isolated from Ananas ananassoides (wild pineapple), also exhibited potential for the post-harvest control of Phytophthora nicotianae infection on Citrus latifolia (Persian lime) [49]. Muscodor suthepensis CMU-Cib462 has been identified as a potential candidate as a post-harvest biofumigant of tangerine fruit to prevent decay [50].

The biofumigation potential of VOCs from different Muscodor species has thus become primers for developing natural as well as interventions which could be effectively used in post-harvest preservation of produce (many of which have been patented). Muscodor cinnanomi has also been reported to produce indole-3-acetic acid (IAA) which stimulates the growth apart from solubilizing toxic metals containing insoluble minerals. This finding opens avenues in exploring the secondary metabolites of Muscodor species as possible biofertilizers or bioinoculants [24].

\section{Pharmaceutical Potential of Muscodor species}

The volatiles produced by Muscodor species have also exhibited significant inhibitory activities against human pathogens during in vitro evaluations thus opening possibilities for their use in pharmaceutical/healthcare settings as volatile antibiotics, disinfectants and sanitizers. The VOCs of Muscodor albus (Cz620) inhibited growth of E. coli and Bacillus subtilis whilst all other isolates of Muscodor, viz. TP-21, KN-26, KN-
27, GP-100, GP-115 and KN-205, exhibited inhibition of E. coli only. Saccharomyces cerevisiae was resistant to VOCs emitted by all other Muscodor isolates [10]. Another isolate of Muscodor albus I-41.3s produced volatiles to which Bacillus subtilis, E. coli and Salmonella typhi were susceptible. Furthermore, artificial compositions based on natural volatile chemistry revealed that the artificial compositions of VOCs were bacteriostatic in nature whilst the one emitted by the fungus was bactericidal [51].

Muscodor crispans (isolate B-23), isolated from wild pineapple (Ananas ananassoides) from the Bolivian Amazon basin [28], exhibited very potent anti-mycobacterial activity apart from S. aureus ATCC6538, Mycobacterium marianum, Yersinia pestis and Salmonella cholereasus. Artificial mixtures of volatile compounds mimicking VOCs of M. crispans exhibited anti-mycobacterial activity against all isolates with exception of one isolate exhibiting Streptomycin resistance. This study indicated that some constituents of volatile gas, possibly through synergistic or additive mode, overcome drug-resistant microbes [52]. Pythiosis is a lifethreatening disease caused by the oomycete Pythium insidiosum sp. nov. In humans, this fungus is responsible for causing peri-orbital cellulitis, keratitis and arteritis. Conventional antifungal drugs are ineffective in treating pythiosis; however, other antifungal drugs such as fluconazole, terbinafine and natamycin have exhibited varying success. $M$. crispans B-23 isolate volatiles were effective against Pythium insidiosum and reduced growth by $80 \%$. Further synthetic mixture of B23 volatiles exhibited a lethal and inhibitory effect against all isolates of $P$. insidiosum [53]. The volatiles of Muscodor fengyangensis (isolates ZJLQ023/ ZJLQ024/ZJLQ070) exhibited antimicrobial activity against E. coli exclusively [54]. Muscodor sutura which was isolated from Prestonia trifidi emanated VOCs which possessed a wide spectrum of antifungal activity and did not exhibit any observable antibacterial and anti-Candida activities [55]. Muscodor kashayum sp. nov. obtained from Aegle marmelos exhibited very potent anti-Candida as well as broad-spectrum antibacterial activity against clinical isolates comprising a microbial test panel [29]. The VOCs of M. kashayum also exhibited inhibition of phytopathogenic fungi. Other novel Muscodor species which have been reported from Asia, viz. M. musae, M. oryzae, M. suthepensis and M. equiseti, produced VOCs exhibiting inhibition to Cryptococcus neoformans as well as the Candida isolates in the antimicrobial test panel. The VOCs elaborated by all the four Muscodor species exerted bactericidal activity against E. coli, Enterococcus faecalis, Proteus mirabilis, Staphylococcus aureus and Pseudomonas pneumoniae [30]. Muscodor strobelii VOCs also exerted broad-spectrum anti-bactericidal activity and very weak antifungal and anti-phytopathogenic activities [31]. The VOCs of Muscodor darjeelingensis exhibited growth inhibition within a range of 11-62\% against test 
panel fungi. A moderate anti-Candida and a weak antibacterial activity were shown by the volatile gas of Muscodor darjeelingensis [56]. Muscodor tigerii on the other hand completely inhibited Alternaria alternata and Cercospora beticola whilst other fungi in the test panel exhibited a suppression in growth between 10 and $70 \%$ in the in vitro VOC stress assay. The growth inhibition against the test panel Candida was further reduced to $50-65 \%$ whilst against bacteria was 50-60\% [57]. Growth suppression between 18 and $77 \%$ was induced by the VOCs of Muscodor ghoomensis whilst a potential antibacterial activity was exhibited against gram-negative bacteria on the test panel. A similar inhibition pattern was observed in the case of VOCs produced by Muscodor indica, which exhibited growth inhibition in the range of $11.5-80.5 \%$. M. indica volatiles exhibited a broadspectrum antibacterial and moderate anti-Candida activity [58].

The VOCs of Muscodor species have helped inspire the development and marketing of an extremely effective antidiarrhoea product for use in veterinary medicine, which prevents 'scouring' in young calves. The US- FDA compliant product contains a formula that has a wide spectrum of antibacterial and antifungal activities as measured both by MICs and gas-Petri plate inhibition studies. Bacteria such as Clostridium spp., pathogenic E. coli and drug-resistant Staphylococcus aureus are targets of this formula called Sx Calf. The product is manufactured and marketed by Ecoplanet Environmental LLC located at Belgrade, MT, USA. More than 200,000 calves have been effectively treated in the USA and Canada. Also, the constituents of this formulation are GRAS (generally recognized as safe), as per US-FDA. The SX Calf formulation also holds some promise in treating diarrhoea based on limited human evaluation studies and approved studies are underway at the US Navy Research Center for confirmation of earlier observations. Sx Calf is also effective against coronaviral caused diseases in farm animals including pigs and cattle and may show promise in treating one or more symptoms of COVID-19 since preliminary in vitro studies have demonstrated that it inactivates SARS-CoV-2 (direct injection to viroid suspension assays) which is currently responsible for a global pandemic [59] [Gary A. Strobel, Ashley Brown, unpublished data]

More recently, non-volatile bioactives of Muscodor are also being explored extensively for their potential medicinal applications. Ethyl acetate extract/ fraction of the culture filtrate of Muscodor indica sp. nov. exhibited a potential broadspectrum antibacterial activity against clinical isolates in an in vitro agar well diffusion assay exhibiting a MIC (minimal inhibitory concentration) between 62.5 and $125 \mu \mathrm{g} / \mathrm{ml}$. Thus, the ethyl acetate extract of $M$. indica holds potential for further isolation and characterization of the bioactive moiety for possible use as an antibacterial antibiotic [60]. Muscodor yucatanensis $\mathrm{Ni} 30$ and its epigenetic variants produced a variety of secondary metabolites. The wild type produced brefeldin A, whilst its epigenetic variants produced ergosterol and xylaguaianol [61]. Brefeldin A has already been established as a polyketide secondary metabolite possessing antibacterial, antifungal and well as anti-viral activities [62]. Muscodor species have also been reported to produce secondary metabolites exhibiting anti-hyperuricemic activity as well as an antioxidant activity whilst carrying out a screening programme on all the novel species of Muscodor isolated from Cinnamomum sp. and Aegle marmelos from India [Sanjai Saxena, unpublished data]. Chloroform extracts of a culture filtrate of $M$. darjeelingensis exhibited potent xanthine oxidase (XO) inhibition, the enzyme responsible for production of uric acid during purine catabolism. The $\mathrm{IC}_{50}$ of the chloroform extract was $0.54 \mu \mathrm{g} / \mathrm{ml}$ which was much lower than allopurinol, the standard drug for treating gout and gouty arthritis. The maximum antioxidant activity was exhibited by $M$. indica in DPPH free radical assay using gallic acid as standard. The antioxidant activity index of chloroform extract of $M$. indica was 7.7 followed by that of M. kashayum at 5.4[63]. Further bioactivity-guided isolation and purification of the chloroform extract of culture filtrate of M. darjeelingensis yielded Luteolin which exhibited XO inhibition as well as antioxidant activity. This is the first report of a plant flavonoid from an endophyte [Neha Kapoor and Sanjai Saxena, unpublished]

A Brazilian research group is exploring the bioactivity of non-volatile compounds from the culture filtrates of select Muscodor species acting as modulators of an enzyme which plays a role in maintaining homoeostasis by improving thrombolytic properties. These non-volatile compounds present in culture filtrate of these selected Muscodor species open up avenues for their possible use as a potential treatment for thrombolytic disease [unpublished information]. Thus, nonvolatile secondary metabolites produced by this sterile endophytic genus have provided promise for other uses of this amazing fungal genus.

\section{Environmental Applications of Muscodor sp.}

The biofumigation potential of Muscodor albus and other species could also be extended for overcoming the growth of fungal contamination in environmental settings after their success in agricultural settings. One such very important setting is indoor air quality and environment under damp or humid conditions in residential buildings due to emissions of malodours and toxins in volatile state by moulds/ toxigenic fungi which may be responsible for a host of respiratory symptoms, respiratory problems and exacerbation of asthma. This is known as sick building syndrome (SBS). Prevention of SBS is an expensive proposition as it involves the removal of infested building material, prevention of further damage caused by 
water or moisture. The mould isolates which are predominantly responsible for SBS are Aspergillus spp., Cladosporium spp., Paecilomyces variotii, Stachybotrys chartarum, Ulocladium botrytis, Wellemia sebi etc. Fungi (epi and endolithic) are also responsible for weathering of stone heritage monuments apart from historic material [64, 65]. Hence, sanitation products are brought in to reduce or prevent the fungal growth such as quaternary ammonium (in liquid phase). However, liquid-based sanitization products have inherent limitations of accessibility in many places in high-rise buildings.

The VOCs being in gas phase could be very effectively used for biofumigation to control the moulds responsible for SBS as well as for other applications in which fungal contaminants are a problem such as on major works of art that become infested with unwanted fungi. Biofumigation with VOCs of Muscodor albus was found to effectively control SBS causing moulds like Cladosporium cladosporioides, Aspergillus niger and Stachybotrys chartarum in a simulated study. Cladosporium cladosporioides was eradicated by the VOCs of Muscodor albus within $48 \mathrm{~h}$ whilst Aspergillus niger and Stachybotrys chartarum were eradicated after $96 \mathrm{~h}$. Hence, VOCs of Muscodor albus prove to be an important intervention for controlling the SBS in residential settings as well as in preserving heritage/historic buildings from fungal infestation [16].

Yet another point source of human pathogens encountered in the environment is sewage from residential dwellings and in the sewage treatment plants. Interestingly, the volatiles of Muscodor albus have been employed for treating human and animal wastes resulting in the reduction of populations of harmful bacteria. Cleanwaste (previously Phillips Environmental Products, Belgrade, MT, USA) has used Muscodor-based proprietary formulations in a product called the WAGBAGs® which had been extensively used by the US defence forces apart for usage in hospitals and recreational settings with portable environmental toilets (PETT®). On wetting by human urine, the Muscodor formulations begin emitting gases which destroy the harmful microorganism's in mixtures of solid as well as liquid human wastes. The Muscodor formulation also helped the decomposition of this human waste after decontamination thereby converting it into a harmless organic substance [66]. This suitably exemplifies the potential of Muscodor species to be evaluated for numerous eco-friendly applications as well as in the bioremediation of problem areas of human dwellings.

\section{Use of Muscodor in Food Preservation}

Prevention of microbial infestation in processed as well as unprocessed food is of immense importance to prevent the spread of food-borne infections and ensure food security. A variety of natural products originating from plants as well as microbes (such as nisin) have been used as food preservatives to prevent microbial growth and deterioration of food products [67]. The VOCs from the pineapple isolate of Muscodor [28] exhibited potential antibacterial as well as antifungal activities against pathogens of plants as well as humans [52]. Interestingly, the majority of the volatiles made by this fungus were on the FDA-GRAS (generally recognized as safe). A biomimetic mixture of these products, termed Flavorzone185-B, is now in the marketplace for plant disease control and other variations of this mixture are in use as food preservatives [Jeneil Biotech Inc., Saukville, WI 53080]. As the biomimetic mixtures of Muscodor VOCs exhibit safety as well as effectiveness, they have given exemplary prevention against Salmonella sp. contaminating the meats such as the beef and poultry. Further testing for meat decontamination is in progress [67]

In addition, a reduced modification of the fungus formula has been demonstrated to be still effective and cheaper to produce [68]. This reduced formula is now in testing for a plethora of uses in medicine, agriculture and industry. The gases produced by other species of Muscodor are also finding applications in the poultry industry. Eggs which form the staple food apart from being considered as an integral component of human balanced diet are contaminated by microorganisms during fertilization, collection, preservation and transportation. The bacterial contamination on the surface of the eggshell moves inside the egg, which not only affects the shelf life but also makes it unfit for human consumption in due course. The microorganisms which contaminate eggs comprise Staphylococcus spp., Salmonella spp., E. coli, Klebsiella spp., Streptococcus spp. and Enterococcus sp. Consumption of contaminated eggs leads to human illness especially food poisoning $[69,70]$. Reducing microbial contamination on the eggshell surface can minimize the chances of infection on consumption apart from increasing the shelf life and contributing to food safety and public health. Fumigation with VOCs of Muscodor cinnanomi in box and cabinet fumigation trials significantly reduced the microbial count on the eggshells significantly after $24 \mathrm{~h}$ as well as after storage for 5, 7 and 14 days. The broad-spectrum antibacterial action of the VOCs of M. cinnamomi holds a promise to be used as a preservative for both processed and unprocessed food [71].

\section{Patents on Muscodor spp.}

A spectrum of patents on Muscodor albus QST 20799 and its isolates was filed by AgraQuest of Davis, CA, USA (now a part of Bayer Crop Science). These patents pertained to the applications in the agriculture sector which have largely been discussed. Today, the genus Muscodor justifies being referred to as an industrially important endophytic genus since $>30$ patents have been granted and dozens of patent applications filed in the USA as well as in other parts of the world since its 
discovery around two decades ago (Fig. 3). These patents include applications in different sectors, viz. agriculture, medicine, environment, food and personal care products, and represent only a fraction of the total number of patents that have issued in other jurisdictions in the world

The industrial relevance of Muscodor lies in its unique volatile chemistry, which is characteristic of all the isolates apart from some common VOCs in present which indicate their inter-relatedness. Incidentally, this relatedness of VOCs is entirely missing in Induratia ziziphi and Induratia thailandica. This is also attributed to its saprobic existence as compared to endophytic existence and evolution of Muscodor species with their host. Some new species such as Muscodor mengyangensis, Muscodor malipoensis and Muscodor menghaiensis have not been brought into the public domain in the form of publications rather have been patented owing to their industrial applications [72-74]. Another very interesting aspect of this genus is its exploitation in the fragrance industry as many isolates are producing fragrance compounds. Across the globe, many scientific groups realizing the commercial worth of this genus are preferring patenting over publication after they find an isolate or a new type species.

\section{Concluding Remarks and Outlook}

The information presented in this review on the genus Muscodor with respect to its biology, ecology and its potential for the development of various commercial products and applications is just the tip of the iceberg. It becomes quite obvious that the fungal genus Muscodor is one of the most promising microbes ever discovered given its promise in promoting the well-being of human-kind in many sectors. Whilst at least 22 species of this organism have been isolated and characterized, one can only wonder how many others remain to be found. It is also obvious that there are intellectual and academic challenges in dealing with this marvellous fungal genus as its biology and role in the world's ecosystems have scarcely even been touched much, hence less understood. One of the most obvious ecological questions is how does it survive in its environment and sustain itself given that no spore forms have ever been observed (Table 1).

Certainly, it appears that the most promising aspect of Muscodor lies in its ability to inhibit and kill other microorganisms and life forms that represent a threat to humans as well as the plants and animals that support mankind. Amazingly, in the case of Muscodor, much of the antimicrobial activity lies in the gas phase of the organism and is not associated with one VOC but by several acting synergistically to bring about the demise of the target organism [10, 28]. In most cases, the individual compounds are already known and are safe $[59,68]$. Additionally, the VOCs are not functional at the level of most commonly used antibiotics and their mode of action is not clearly understood, but nevertheless, they can be used to treat plant-, animal- and hopefully in the future human-associated diseases.

The number of patents granted, products commercialized and patent applications under process for grant of patent clearly reflects the commercial potential of this fungal genus. Commercial organizations generally obtain complete genomic information of the microorganisms being exploited to ensure their identity, as well as genetic makeup to completely harness their potential (through strain improvement). In the case of Muscodor also, the whole genomic signatures have been obtained by Britney Spears of MBI (Marrone Bio Innovations, personnel communication). Interestingly, only 4 partial DNA sequences of some selected Induratia species, viz. Induratia zizhiphi and Induratia thailandica, were obtained by
Fig. 3 Patients* granted on members of the genus Muscodor in last 15 years. *Refers to selected countries, primarily USA, Europe, Canada and China. Information collated based on protologue publications and patents

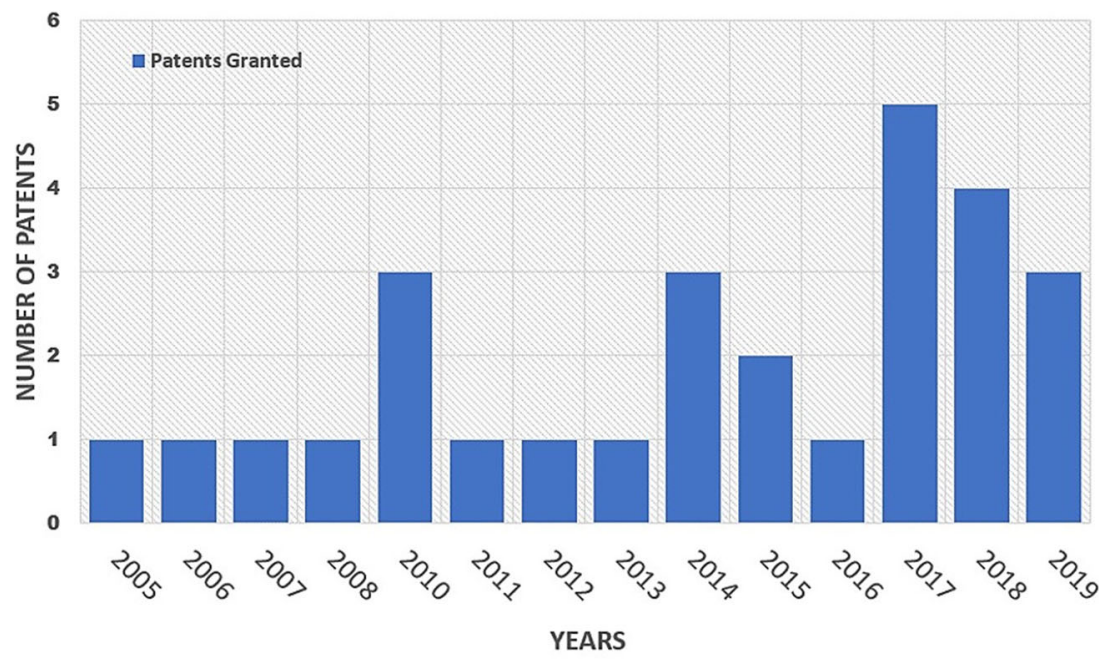

* Refers to selected countries, primarily, USA, Europe, Canada and China Information collated based on protologue publications and patents 
Samarakoon et al. [7] and an attempt to fuse and subsequently eliminate the genus Muscodor with an earlier named fungal genus Induratia is an inconclusive attempt based on the wellstudied VOC chemistries, ecological niches occupied and other structural and biological bases of Muscodor spp. that have been described in this report. This substantiates our view point and concept that Muscodor genus can never be renamed to Induratia until the whole genomic comparisons between the two genera are carried out and their volatilome and metabolome show similarities in biosynthetic pathways [75]. Thus, one can conclude with confidence that the genus Muscodor is alive and different from Induratia, with many promising and novel applications from it are on the way.

\section{Compliance with Ethical Standards}

Conflict of Interest The authors declare that they have no conflict of interest.

\section{References}

1. Worapong J, Strobel G, Ford E, Li J, Baird G, Hess W (2001) Muscodor albus gen. et sp. nov. an endophyte from Cinnamomum zeylanicum. Mycotaxon 79:67-79

2. Strobel G, Dirksie E, Sears J, Markworth C (2001) Volatile antimicrobials from a novel endophytic fungus. Microbiol 147:29432950

3. Strobel G, Daisy B (2003) Bioprospecting for microbial endophytes and their natural products. Microbiol Mol Biol Rev 67:491-502

4. Strobel G (2006) Muscodor albus and its biological promise. J Ind Microbiol Biotechnol 33:514-522

5. Strobel G (2011) Muscodor albus and its biological promise. Phytochem Rev 10:165-172

6. Strobel G (2012) Muscodor albus -the anatomy of an important biological discovery. Microbiol Today 39:108-111

7. Samarakoon M, Thongbai B, Hyde K, Bronstrup M, Beutling U, Lambert C, Miller A, Liu J-K, Promputtha I, Stadler M (2020) Elucidation of the life cycle of the endophytic genus Muscodor and its transfer to Induratia in Induratiaceae fam. nov., based on a polyphasic taxonomic approach. Fungal Divers 101:177-210

8. Xie J, Strobel GA, Mends M, Hilmer J, Nigg J, Geary B (2013) Collophora aceris, a novel antimycotic producing endophyte associated with Douglas maple. Microb Ecol 66:784-795

9. Chen JJ, Feng X, Xia CY, Kong D, Qi ZY, Liu F, Chen D, Lin F, Zhang C (2019) Confirming the phylogenetic position of the genus Muscodor and the description of a new Muscodor species. Mycosphere 10(1):187-201

10. Ezra D, Hess W, Strobel G (2004) Unique wild type endophytic isolates of Muscodor albus, a volatile antibiotic producing fungus. Microbiol 150:4023-4031

11. Alpha-Cobb C, Campos M, Jacobs-Wagner C, Strobel S (2015) Mycofumigation by the volatile organic compound-producing fungus Muscodor albus induces bacterial cell death through DNA damage. Appl Envirnon Microbiol 81:1147-1156

12. Hutchings M, Alpha-Cobb C, Hiller D, Berro J, Strobel S (2017) Mycofumigation through production of the volatile DNA methylating agent $\mathrm{N}$-methyl- nitrosoisobutyramide by fungi in the Genus Muscodor. J Biol Chem 292:7358-7371

13. Banerjee D, Strobel G, Geary B, Sears J, Ezra D, Liarzi O, Combs J (2010) Muscodor albus strain GBA, an endophytic fungus of
Gingko biloba from the United States of America, produces volatile antimicrobials. Mycology 1:179-186

14. Strobel G, Bui V, Hai S, Himmel P, Marrone P, Xing L, Lewis S (2013) Muscodor albus strain producing volatile organic compounds and methods of use. US PTO -Appl No. US20140086879A1.

15. Strobel G, Kluck K, Hess WM, Sears J, Ezra D, Vargas P (2007) Muscodor albus E-6, an endophyte of Guazuma ulmifolia, making volatile antibiotics: isolation, characterization and experimental establishment in the host plant. Microbiol. 153:2613-2620

16. Mercier J, Jiminez J (2007) Potential of the volatile - producing fungus Muscodor albus for the control of building molds. Can J Microbiol 53:404-410

17. Mercier J, Jimenez J (2009) Demonstration of the biofumigation activity of Muscodor albus against Rhizoctonia solani in soil and potting mix. Biocontrol 54:797-805

18. Stinson AM, Zidack NK, Strobel GA, Jacobsen BS (2003) Mycofumigation with Muscodor albus and Muscodor roseus for controlling seedling diseases in Sugar beet and Verticillium wilt in Egg plant. Plant Dis 87:1349-1354

19. Mercier J, Manker DC (2005) Biocontrol of soil borne diseases and plant growth enhancement in soilless mix by the volatile producing fungus M. albus. Crop Prot 24(4):355-362

20. Camp AR, Dillard HR, Smart CD (2008) Efficacy of Muscodor albus for the control of Phytophthora blight of sweet pepper and butternut squash. Plant Dis 92:1488-1492

21. Worapong J, Strobel GA (2009) Biocontrol of a root rot of kale by Muscodor albus strain MFC2. BioControl 54:301-306

22. Goates BJ, Mercier J (2009) Effect of biofumigation with volatiles from Muscodor albus on viability of Tilletia spp. teliospores. Can J Microbiol 55:203-206

23. Goates BJ, Mercier J (2011) Control of common bunt of wheat under field conditions with biofumigation fungus Muscodor albus. Eur J Plant Pathol 131:403-407

24. Suwannarach N, Kumla J, Matsui K, Lumyong S (2015) Characterization and efficacy of Muscodor cinnamomi in promoting plant growth and controlling Rhizoctonia root rot in tomatoes. Biol Control 90:25-33

25. Siri-udom S, Suwannarch N, Lumyong S (2016) Existence of Muscodor vitigenus, Muscodor equiseti and Muscodor heveae sp. nov. in leaves of the rubber tree (Hevea brasiliensis Müll.Arg.), and their biocontrol potential. Ann Microbiol 66:473-448

26. Siri-udom S, Suwannarch N, Lumyong S (2017) Applications of volatile compounds acquired from $M$. heveae against white root rot disease in rubber tree (Hevea brasiliensis Müll.Arg.), and relevant allelopathy effects. Fungal Biol 121:573-581

27. Pena LC, Jung FJ, Savi DC, Servienski A, Aluizio R, Goulin EH, Galli-Terasava LV, de Noronha Salaes Maia BH, Annies V, Franco CRC, Glienke C, Kava V (2017) A Muscodor strain isolated from Citrus sinensis and its production of volatile organic compounds inhibiting Phyllosticta citricarpa growth. J Plant Dis Prot 124:349360

28. Mitchell AM, Strobel GA, Hess WM, Vargas PN, Ezra D (2008) Muscodor crispans, a novel endophyte from Ananas ananassoides in the Bolivian Amazon. Fungal Divers 31:37-43

29. Meshram V, Kapoor N, Saxena S (2013) Muscodor kashayum sp. nov. - a new volatile anti-microbial producing endophytic fungus. Mycology 4:196-204

30. Suwannarach N, Kumla J, Bussaban B, Hyde KD, Matsui K, Lumyong S (2013) Molecular and morphological evidence support four new species in the genus Muscodor from northern Thailand. Ann Microbiol 63:1341-1351

31. Meshram V, Saxena S, Kapoor N (2014) Muscodor strobelii, a new endophytic species from South India. Mycotaxon 128:93-104

32. Bolton DM, Eaton LG (1968) In: Stecher PG, Windholz M, Leahy DS (eds) MERCK Index8th edn. Merck, Rahway, p 713 
33. Daisy BH, Strobel GA, Castillo U, Ezra D (2002) Naphthalene, an insect repellent, is produced by Muscodor vitigenus, a novel endophytic fungus. Microbiology 148(11):3737-3741

34. Lee WL, Lacey LA, Bishop BJB (2009) Pupal mortality and adult emergence of western cherry fruit fly (Diptera: Tephritidae) exposed to the fungus Muscodor albus (Xylariales: Xylariaceae). J Econ Entomol 102(6):2041-2047

35. Reyes M, Franck P, Charmillot PJ, Ioriatti C, Olivares J, Pasqualini E, Sauphanor B (2007) Diversity of insecticide resistance mechanisms and spectrum in European populations of the codling moth, Cydia pomonella. Pest Manag Sci 63:890-902

36. Lacey LA, Horton DR, Jones DC, Headrick HL, Neven LG (2009) Efficacy of the biofumigant fungus Muscodor albus (Ascomycota: Xylariales) for control of codling moth (Lepidoptera: Tortricidae) in simulated storage conditions. J Econ Entomol 102(1):43-49

37. Lacey LA, Horton DR, Jones DC (2008) The effect of temperature and duration of potato tuber moth (Lepiodoptera: Gelechiidae) in infested tubers to the biofumigant fungus M. albus. J Invertebr Pathol 97:159-164

38. Riga E, Lacey LA, Guerra N (2008) Muscodor albus, a potential biocontrol agent against plant-parasitic nematodes of economically important vegetable crops in Washington State, USA. Biol Control 45:380-385

39. Grimme E, Zidack NK, Sikora RA, Strobel GA, Jacobsen BJ (2007) Comparison of Muscodor albus volatiles with a biorational mixture for control of seedling diseases of sugarbeet and root know nematode on tomato. Plant Dis 91:220-224

40. Sivakumar D, Bautista-Baños S (2014) A review on the use of essential oils for postharvest decay control and maintenance of fruit quality during storage. Crop Prot 64:27-37

41. Mercier J, Jimenez JI (2004) Control of fungal decay of apples and peaches by the biofumigant fungus Muscodor albus. Postharvest Biol Technol 31:1-8

42. Mercier J, Smilanick JL (2005) Control of green mold and sour rot of stored lemon by biofumigation with Muscodor albus. Biol Control 32:401-407

43. Schnabel G, Mercier J (2006) Use of a Muscodor albus pad delivery system for the management of brown rot of peach in shipping cartons. Postharvest Biol Technol 42:121-123

44. Ramin AI, Prange RK, Braun PG, Delong JM (2007) Biofumigation of post-harvest apples decay with Muscodor albus volatiles. J Appl Sci Res 3(4):307-310

45. Schotsmans WC, Braun G, Delong JM, Prange RK (2008) Temperature and controlled atmosphere effects on efficacy of Muscodor albus as a biofumigant. Biol Control 44:101-110

46. Mercier J, Lego SF, Smilanick JL (2010) In-package use of Muscodor albus volatile-generating sachets and modified atmosphere liners for decay control in organic table grapes under commercial conditions. Fruits 65:31-38

47. Gabler FM, Mercier J, Jimenez JI (2010) Smilanick JL (2010) Integration of continuous biofumigation with Muscodor albus with pre-cooling fumigation with ozone or sulphur dioxide to control postharvest gray mold of grapes. Postharvest Biol Technol 55:7884

48. Corcuff R, Mercier J, Tweddell R, Arul J (2011) Effect of water activity on the production of volatile organic compounds by Muscodor albus and their effect on three pathogens in stored potato. Fungal Biol 115:220-227

49. Banguela-Castillo A, Ramos-Gonzalez PL, Pena-Marey M, Tanaka FAO, Blassioli-Moraes MC, Hernandez-Rodríguez L, Cabrera RI (2015) The same host but a different Muscodor: a new Muscodor albus isolate from wild pineapple (Ananas ananassoides) with potential application in agriculture. Crop Prot 78:284-292

50. Suwannarach N, Bussaban B, Nuangmek W, Pithankpol W, Jirawattanakul B, Matsui K, Lumyong S (2016) Evaluation of Muscodor suthepensis strain CMU-Cib462 as a postharvest biofumigant for tangerine fruit rot caused by Penicillium digitatum. J Sci Food Agric 96:339-345

51. Atmosukarto I, Castillo U, Hess WM, Sears J, Strobel G (2010) Isolation and characterization of M. albus I-41.3 s, a volatile antibiotic producing fungus. Plant Sci 169(5):854-861

52. Mitchell AM, Strobel GA, Moore E, Robison R, Sears J (2010) Volatile antimicrobials from Muscodor crispans, a novel endophytic fungus. Microbiology 156:270-277

53. Theerapong K, Lowhnoo T, Yingyong W, Rujirawat T, Fucharoen S, Strobel GA (2012) In vitro antimicrobial activity of volatile organic compounds from Muscodor crispans against the pathogenic oomycete Pythium insidiosum. Southeast Asian J Trop Med Public Health 43:1474-1483

54. Zhang CL, Wang GP, Mao LJ, Komon-Zelazowska M, Yuan ZL, Lin FC, Druzhinina IS, Kubicek CP (2010) Muscodor fengyangensis sp. nov. from southeast China: morphology, physiology and production of volatile compounds. Fungal Biol 114(10): 797-808

55. Kudalkar P, Strobel G, Riyaz-Ul-Hassan S, Geary B, Sears J (2012) Muscodor sutura, a novel endophytic fungus with volatile antibiotic activities. Mycoscience 53:319-325

56. Saxena S, Meshram V, Kapoor N (2014) Muscodor darjeelingensis, a new endophytic fungus of Cinnamomum camphora collected from north-eastern Himalayas. Sydowia 66: 55-67

57. Saxena S, Meshram V, Kapoor N (2015) Muscodor tigerii sp. nov. volatile antibiotic producing endophytic fungus from the Northeastern Himalayas. Ann Microbiol 65:47-57

58. Meshram V, Gupta M, Saxena S (2015) Muscodor ghoomensis and Muscodor indica: new endophytic species based on morphological features, molecular and volatile organic analysis from Northeast India. Sydowia 67:133-146

59. Strobel GA, Blatt B (2019) Volatile organic compound formulations having antimicrobial activity. European Patent, EP 3017054 B1, 13.11.2019, Proprietor: EcoPlanet Environmental LLC Belgrade, MT 59714 (US)

60. Boparai JK, Saxena S, Meshram V (2015) In vitro antimicrobial potential of Indian Muscodor species. J Basic Appl Mycol 11:2225

61. Qadri M, Nalli Y, Jain SK, Chaubey A, Ali A, Strobel GA, Vishwakarma VA, Riyaz-Ul-Hassan S (2017) An insight into the secondary metabolism of Muscodor yucatanensis: small-molecule epigenetic modifiers induce expression of secondary metabolismRelated genes and production of new metabolites in the endophyte. Microb Ecol 73(4):954-965

62. Betina V (1992) Biological effects of the antibiotic brefeldin A (decumbin, cyanein, ascotoxin, synergisidin): a retrospective. Folia Microbiol (Praha) 37(1):3-11

63. Kapoor N, Saxena S (2016) Xanthine oxidase inhibitory and antioxidant potential of Indian Muscodor species. 3 Biotech 6:248

64. Sterflinger K, Prillinger H (2001) Molecular taxonomy and biodiversity of rock fungal communities in an urban environment (Vienna, Austria). Antonie Van Leeuwenhoek 80:275-286

65. Sterflinger K (2005) Black yeasts and meristematic fungi: ecology, diversity and identification. In: Rosa C, Gabor P (eds) Yeast Handbook. Biodiversity and Ecophysiology of Yeasts, vol 1. Springer, New York, pp 501-514

66. Strobel GA, Ezra D (2008) Application of Muscodor albus to control harmful microbes in animals and wastes. Patent no. US 7,341, 862 B2, 11.03.2008, Assignee: Montana State University, Bozeman, MT (US)

67. Faith N, Garda G, Skebba V, Gandhi NR, Cruprynski C (2014) Use of a commercial mixture of volatile compounds from the fungus Muscodor to inhibit Salmonella in ground turkey and beef. Food Control 47:628-633 
68. Gandhi NR, Skebba VP, Strobel GA (2019) Antimicrobial compositions and related methods of use. Patent no. US 10,383,332 B2, Assignee: Jeneil Biosurfactant Company LLC, USA

69. Kone AZ, Jan S, Le Marechal C, Grosset N, Gautier M, Puterflam J, Baron F (2013) Identifying risk factors for eggshell contamination by Bacillus cereus group bacteria in French laying farms. Br Poult Sci 54:298-305

70. Chaemsanit S, Akbar A, Anal AK (2015) Isolation of total aerobic and pathogenic bacteria from table eggs and its contents. Food Appl Biosci J 3:1-9

71. Suwannarach N, Kaewyana C, Yodmeeklin A, Kumla J, Matsui K, Lumyong S (2017) Evaluation of Muscodor cinnamomi as an egg biofumigant for the reduction of microorganisms on the eggshell surface and its effect on egg quality. Int J Food Microbiol 244:5261

72. Guo S, Tan X, Chen X, Wang C (2017) Muscodor mengyangensis having biological prevention and control effects. Patent no. $\mathrm{CN}$
104419649A (Chinese), 15.9.2017, Assignee: Institute of Medicinal Plants and Development \& Chinese Academy of Medical Sciences (CAMS).

73. Guo S, Tan X, Chen X, Xing Y, Wang C (2017) Muscodor malipoensis with biocontrol effect. Patent no. CN 104419647A (Chinese), 09.06.2017, Assignee: Institute of Medicinal Plants and Development \& Chinese Academy of Medical Sciences (CAMS).

74. Guo S, Chen X, Tan X, Wang C (2017) Muscodor menghaiensis having biological prevention and control effect. Patent no. CN 104419648A (Chinese), 09.06.2017, Assignee: Institute of Medicinal Plants and Development \& Chinese Academy of Medical Sciences (CAMS).

75. Bailly A, Weisskopf L (2017) Mining the volatilomes of plantassociated microbiota for new biocontrol solutions. Front Microbiol 8. https://doi.org/10.3389/fmicb.2017.01638 